\title{
Retroviral induction of GSK-3 $\beta$ expression blocks the stimulatory action of physical exercise on the maturation of newborn neurons
}

\author{
María Llorens-Martín $^{1,2}$ - Catia M. Teixeira ${ }^{3} \cdot J^{2}$ erónimo Jurado-Arjona ${ }^{1,2} \cdot$ Randeep Rakwal $^{4,5}$. \\ Junko Shibato $^{5,6} \cdot$ Hideaki Soya $^{6} \cdot$ Jesús Ávila $^{1,2}$
}

Received: 9 December 2015/Revised: 10 March 2016/Accepted: 11 March 2016/Published online: 24 March 2016

(C) Springer International Publishing 2016

\begin{abstract}
Adult hippocampal neurogenesis (AHN) is a key process for certain types of hippocampal-dependent learning. Alzheimer's disease (AD) is accompanied by memory deficits related to alterations in AHN. Given that the increased activity of GSK-3 $\beta$ has been related to alterations in the population of hippocampal granule neurons in $\mathrm{AD}$ patients, we designed a novel methodology by which to induce selective GSK-3 $\beta$ overexpression exclusively in newborn granule neurons. To this end, we injected an rtTA-IRES-EGFP-expressing retrovirus into the hippocampus of tTO-GSK-3 $\beta$ mice. Using this novel retroviral strategy, we found that GSK-3 $\beta$ caused a cellautonomous impairment of the morphological and synaptic maturation of newborn neurons. In addition, we examined whether GSK-3 $\beta$ overexpression in newborn neurons limits
\end{abstract}

M. Llorens-Martín and C. M. Teixeira contributed equally to this work.

Electronic supplementary material The online version of this article (doi:10.1007/s00018-016-2181-6) contains supplementary material, which is available to authorized users.

María Llorens-Martín

m.1lorens@csic.es

$\bowtie$ Jesús Ávila

javila@cbm.csic.es

1 Centro de Biología Molecular "Severo Ochoa" (CSICUAM), Universidad Autónoma de Madrid, c/Nicolás Cabrera 1, 28049 Madrid, Spain

2 Centro de Investigación Biomédica en Red sobre Enfermedades Neurodegenerativas (CIBERNED, ISCIII), c/ Valderrebollo 5, Madrid, Spain

3 Emotional Brain Institute, Nathan Kline Institute, New York, NY, USA the effects of physical activity. While physical exercise increased the number of dendritic spines, the percentage of mushroom spines, and the head diameter of the same in tetOFF cells, these effects were not triggered in tet-ON cells. This observation suggests that GSK-3 $\beta$ blocks the stimulatory actions of exercise. Given that the activity of GSK$3 \beta$ is increased in the brains of individuals with $A D$, these data may be relevant for non-pharmacological therapies for AD.

Keywords GSK-3 $\beta$ - Physical exercise . Adult neurogenesis · Hippocampus · Retrovirus · rtTA

\section{Introduction}

Newborn neurons are continuously added to the dentate gyrus (DG) throughout life [1]. Dendritic trees increase in complexity during the differentiation of developing granule neurons. These cells become fully integrated in the

$4 \quad$ Faculty of Health and Sport Sciences and Tsukuba International Academy for Sport Studies (TIAS), University of Tsukuba, Tsukuba, Ibaraki 305-8574, Japan

5 Global Research Center for Innovative Life Science, School of Pharmacy and Pharmaceutical Sciences, Hoshi University, Shinagawa, Tokyo 142-8501, Japan

6 Laboratory of Exercise Biochemistry and Neuroendocrinology, Faculty of Health and Sport Sciences, University of Tsukuba, Tsukuba, Ibaraki 305-8574, Japan 
trisynaptic circuit and are finally functionally indistinguishable from surrounding mature granule neurons at the end of the maturational process [2].

Adult hippocampal neurogenesis (AHN) is a dynamic process regulated by external stimuli [3]. Stress and aging are known to decrease AHN [4, 5]. In addition, impairments in AHN have been described in neurodegenerative diseases such as Alzheimer's disease (AD) [6, 7]. In contrast, one of the strongest positive modulators of AHN is physical exercise [8]. Exercise exerts neuroprotective actions not only in healthy subjects, but also in AD patients $[9,10]$, whereas a sedentary lifestyle is considered a risk factor for sporadic $\mathrm{AD}$ [11]. Although the molecular mechanisms by which exercise acts on the brain are not fully understood, one of the most relevant notions, the "neurotrophic hypothesis", postulates that exercise increases the levels of neurotrophic factors in the brain [12, $13]$, thereby counteracting the overactivation of proteins such as glycogen synthase kinase-3 $\beta$ (GSK-3 $\beta$ ), observed in $\mathrm{AD}$ patients [14]. Although some of the behavioral effects exerted by exercise are mediated by an increase in AHN [15], other effects have been demonstrated to be AHN-independent [16]. In addition, it is still a matter of debate whether the effects on this process occur in a similar way in healthy and AD brains-the latter marked by dysregulation of the activity of certain toxic proteins [17].

Indeed, using a transgenic model in which GSK-3 $\beta$ overexpression is driven by the neuronal promoter CamKII, we found the alterations in newborn granule neurons strikingly similar to those described in AD patients [18]. However, non-cell-autonomous events, namely neuroinflammation, also contribute to the development of the aforementioned alterations in these mice [19].

Thus, to address the participation of GSK- $3 \beta$ in mediating the effects of physical exercise on the brain, we developed a novel methodology, based on the use of tetracycline-regulated elements, to selectively induce GSK$3 \beta$ overexpression in newborn neurons.

Tetracycline-regulated systems have been traditionally used to drive conditional gene expression both in vivo and in vitro [20]. The specific regulation of these systems is achieved through the Tetracycline-regulated transactivator (tTA) [21]. This protein binds specifically to the tetO operator sequence and induces transcription of the transgene of interest from an adjacent cytomegalovirus (CMV) minimal promoter. The combination of the tTA and the tetO elements thus allows for conditional overexpression of a given transgene both in vivo and in vitro [22]. In addition, Tetracycline (and its analog Doxycycline) can bind to the tTA, triggering a conformational change, which prevents tTA's binding to the tetO operator. Conversely, other constructs, such as the retro-tTA (rtTA), are able to bind to the tetO only in the presence of Doxycycline [23].
In combination with the aforementioned systems, a plasmid carrying the bidirectional tet-responsive promoter [24], followed by both a GSK-3 $\beta$ cDNA in one direction, and in the other, a $\beta$-Galactosidase ( $\beta$-Gal) cDNA fused to a nuclear localization signal (BitetO construct), was generated by Lucas et al. [22]. This BitetO construct was microinjected into murine oocytes, thus generating a transgenic line of mice designated as tTO-GSK-3 $\beta$. To selectively induce GSK-3 $\beta$ overexpression in newborn granule neurons, we stereotaxically injected an rtTA-IRESEGFP-expressing retrovirus into the hippocampus of tTOGSK-3 $\beta$ mice, in which GSK-3 $\beta$ is expressed exclusively in the newborn neurons infected by the retrovirus, following binding of the active rtTA element to the tetO promoter in the presence of Doxycycline. The rtTA element, as previously mentioned, binds the tetO operator in the presence of Doxycycline [23].

This the first time, to the best of our knowledge, that a retroviral system containing an rtTA element has been used to drive the selective expression of a given protein exclusively in hippocampal newborn neurons. Importantly, we evaluated the cell-autonomous effects of GSK-3 $\beta$ overexpression on newborn neurons and whether this overexpression limits the effectiveness of physical exercise. GSK-3 $\beta$ caused striking cell-autonomous effects on the synaptic and morphological maturation of newborn neurons. Moreover, given the absence of these effects in GSK-3 $\beta$-overexpressing cells, we demonstrate that GSK$3 \beta$ overexpression limits the stimulatory effects of physical exercise on newborn granule neurons. As that the activity of GSK-3 $\beta$ appears to be increased in the brains of $\mathrm{AD}$ patients, these findings may be clinically relevant for $A D$ therapies, as this kinase appears to determine the efficacy of physical exercise on the functional maturation of newborn granule neurons.

\section{Materials and methods}

\section{Animals}

tTO-GSK-3 $\beta$ mice were generated as previously described [22]. Briefly, a plasmid carrying the bi-directional tet-responsive promoter (tetO) [24] followed by a GSK-3 $\beta$ cDNA in one direction and a cDNA encoding $\beta$-Galactosidase ( $\beta$-Gal) fused to a nuclear localization signal in the other, was generated. The tetO construct was then microinjected into oocytes, and the transgenic mouse lines were designated as tTO-GSK-3 $\beta$. This plasmid alone had no effect on GSK-3 $\beta$ expression [22]. After co-transfection with a plasmid that allows for the expression of the Tetracycline-regulated transactivator (tTA), a marked increase in GSK-3 $\beta$ expression was observed. This increase 
resulted in increased phosphorylation of Tau, as demonstrated by Western blotting with anti phospho-Tau (PHF-1 epitopes), which recognizes Tau phosphorylation by GSK$3 \beta[22]$.

Animals were housed in a specific pathogen-free colony facility in accordance with European Community Guidelines (directive 86/609/EEC) and handled following European and local animal care protocols. Five mice per experimental condition and time point were used for the retroviral injections. Only female mice were used to avoid undesired effects of dominance hierarchy on AHN. Animals were housed in groups of five per cage.

\section{Retroviruses}

A retroviral vector containing the reverse Tetracyclineregulated transactivator (rtTA), the internal ribosome entry site (IRES), and EGFP (rtTA-IRES-EGFP retrovirus) was purchased from AddGene (reference number PMA2640). Figure 1a shows a schematic diagram of the retroviral rtTA-IRES-EGFP plasmid structure. The rtTA element is inactive in its native form. In the presence of Doxycycline, a conformational change takes place in this element, allowing it to bind to the tetO promoter, thus triggering the expression of both GSK-3 $\beta$ and $\beta-G a l$. Thus, Doxycycline treatment allows the overexpression of GSK-3 $\beta$ in newborn granule neurons of the desired age (Fig. 1b).

Since the retroviruses used are engineered to be replication-incompetent, they insert their genetic material only into cells undergoing cell division at the time of infection. This system allows the selective expression of GSK-3 $\beta$ in newborn neurons. The number of cells infected by the rtTA-IRES-EGFP retrovirus was similar to that obtained in the case of the infection with EGFP-expressing retroviruses (data not shown). Activation of the system can be checked by the expression of either $\beta$-Gal or EGFP reporters. To test the activity of GSK-3 $\beta$ in these cells, the fluorescence intensity for phospho-Tau was measured in individual $\mathrm{EGFP}^{+}$cells.

Retroviral stocks were concentrated to working titers of $1 \times 10^{7}$ to $2 \times 10^{8} \mathrm{pfu} / \mathrm{ml}$ by ultracentrifugation [2].

\section{Stereotaxic surgery}

Mice were anesthetized with isoflurane and placed in a stereotaxic frame. Coordinates $(\mathrm{mm})$ relative to bregma in the anteroposterior, mediolateral, and dorsoventral axes were as follows: dentate gyrus (DG) $(-2.0,1.4$, 2.2). $2 \mu \mathrm{l} / \mathrm{DG}$ of virus solution was infused at a rate of $0.2 \mu \mathrm{l} / \mathrm{min}$ via a glass micropipette in both hemispheres. Animals were 8-weeks-old at the time of retroviral injections.

\section{Experimental design and treatments}

For the validation of the rtTA/tTO system, mice received doxycycline $(2 \mathrm{~g} / \mathrm{l})$ in drinking water (tet-ON mice) or water alone (tet-OFF mice). Doxycycline treatments began $12 \mathrm{~h}$ before the retroviral injections. Animals were killed at $24,48 \mathrm{~h}$ or 1 week after retroviral injection to assess the activation of the transgenic system. The percentage of $\mathrm{EGFP}^{+}$cells that expressed $\beta$-Gal was measured at the aforementioned time points. In addition, to ensure the selective long-term activation of the transgenic system in newborn neurons, the phosphorylation of the neuronal Tau protein (the main substrate of GSK-3 $\beta$ kinase activity), was measured in individual cells.

To study the effects of physical exercise, mice were randomly assigned to one of four conditions: sedentary tetOFF, sedentary tet-ON, exercise tet-OFF, and exercise tetON. Two weeks after retroviral injections, animals in the exercise groups were allowed to run freely in voluntary running wheels for two additional weeks. Finally, all mice were killed 4 weeks after retroviral injections. The 2-week post-injection interval was selected as the starting point of physical exercise training, given that the period of maximal responsiveness of newborn neurons to the effects of this stimulus and also to environmental enrichment begins at this cell age [25].

\section{Sacrifice}

Mice were fully anesthetized with an intraperitoneal pentobarbital injection (EutaLender, Normon Laboratories, Madrid, Spain; $60 \mathrm{mg} / \mathrm{kg} \mathrm{bw}$ ) and transcardially perfused with saline followed by $4 \%$ paraformaldehyde in phosphate buffer. Brains were immediately removed and postfixed overnight in the same fixative.

\section{Immunohistochemistry}

Sagittal brain sections were obtained on a Leica VT1200S vibratome (50- $\mu \mathrm{m}$ thick sections). For immunohistochemical analysis, a series of brain slices were made up randomly of one section from every ninth. Slices were initially pre-incubated in phosphate buffer with $1 \%$ Triton $\mathrm{X}-100$ and $1 \%$ bovine serum albumin, and then dual immunohistochemistry was performed as described previously [26]. The primary antibodies used were as follows: mouse anti- $\beta$-Galactosidase (Promega, Madison, WI, USA; 1:3000); rabbit anti-GFP (Invitrogen, Carlsbad, CA, USA; 1:1000); goat anti-doublecortin (DCX) (Santa Cruz Biotechnologies, Dallas, TX, USA; 1:500); mouse anti GFAP (Promega, Madison, WI, USA; 1:1000); mouse antiNeuN (Life Technologies, Grand Island, NY, USA; 1:1000); and mouse anti-phospho-Tau (PHF-1 epitope) (a 


\section{A}
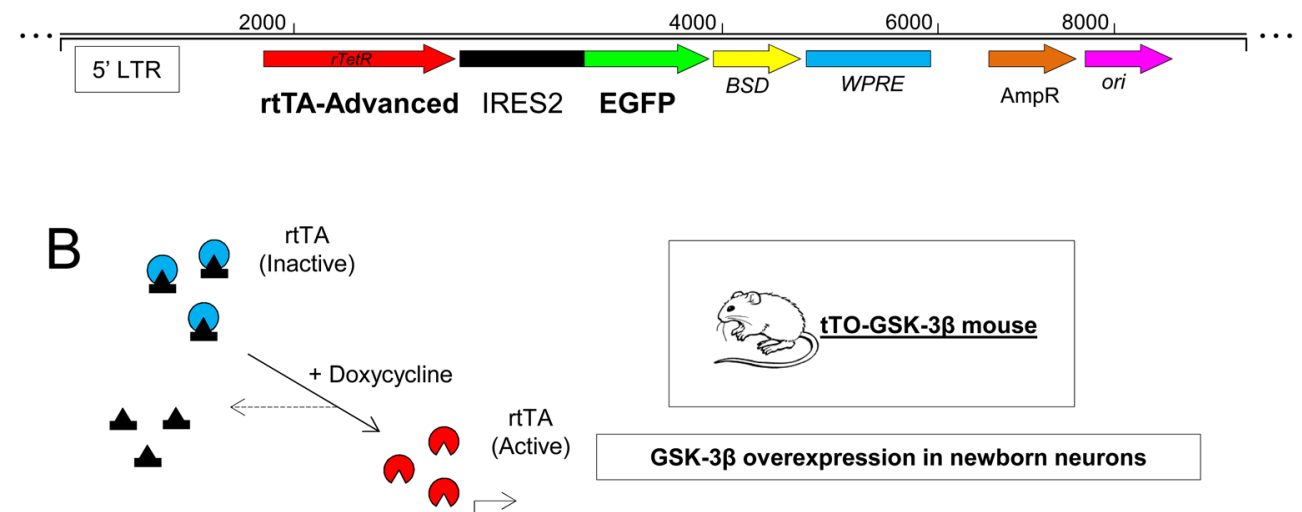

$\beta$-Galactosidase $\leftarrow$ tetO $\quad$ GSK-3 $\beta$
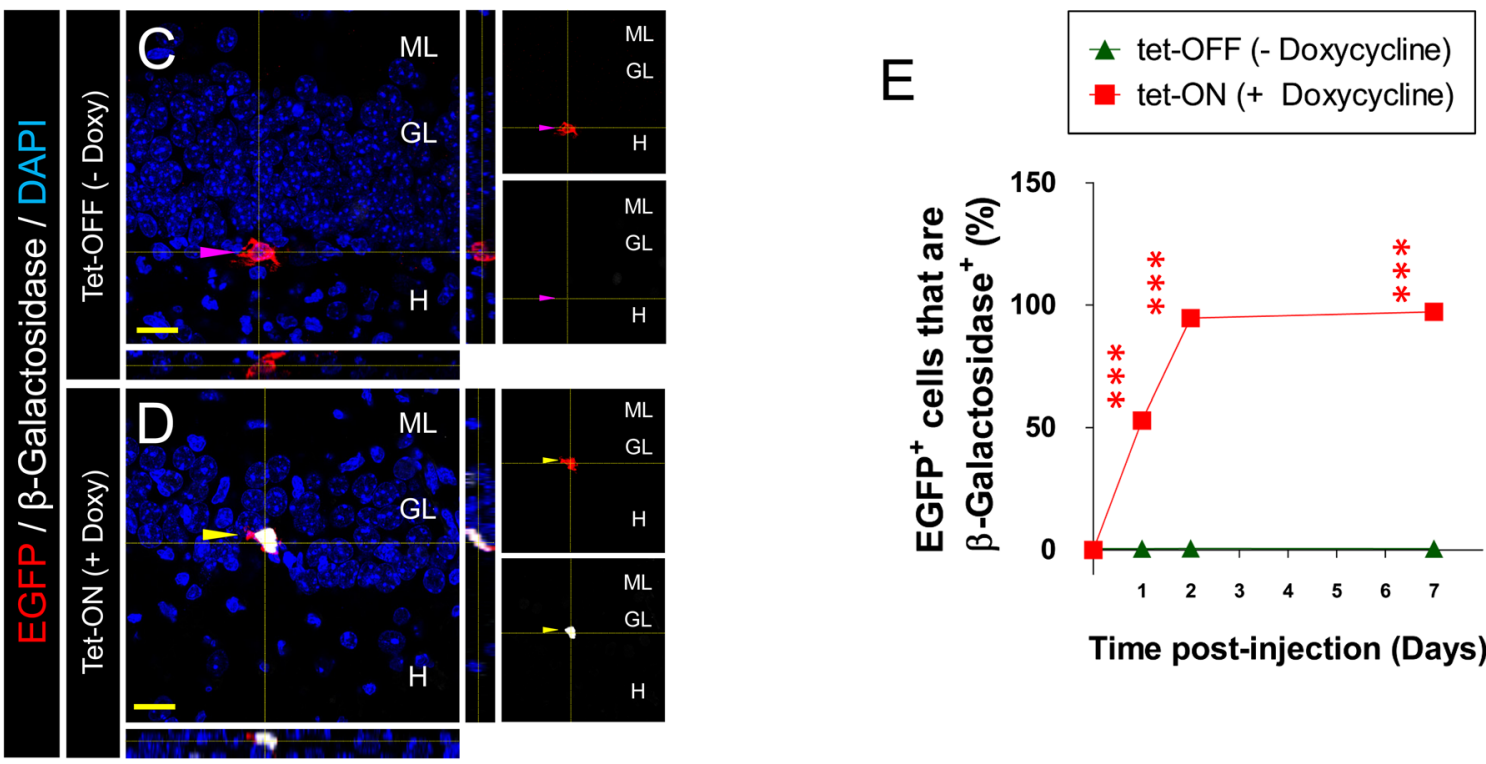

Time post-injection (Days)
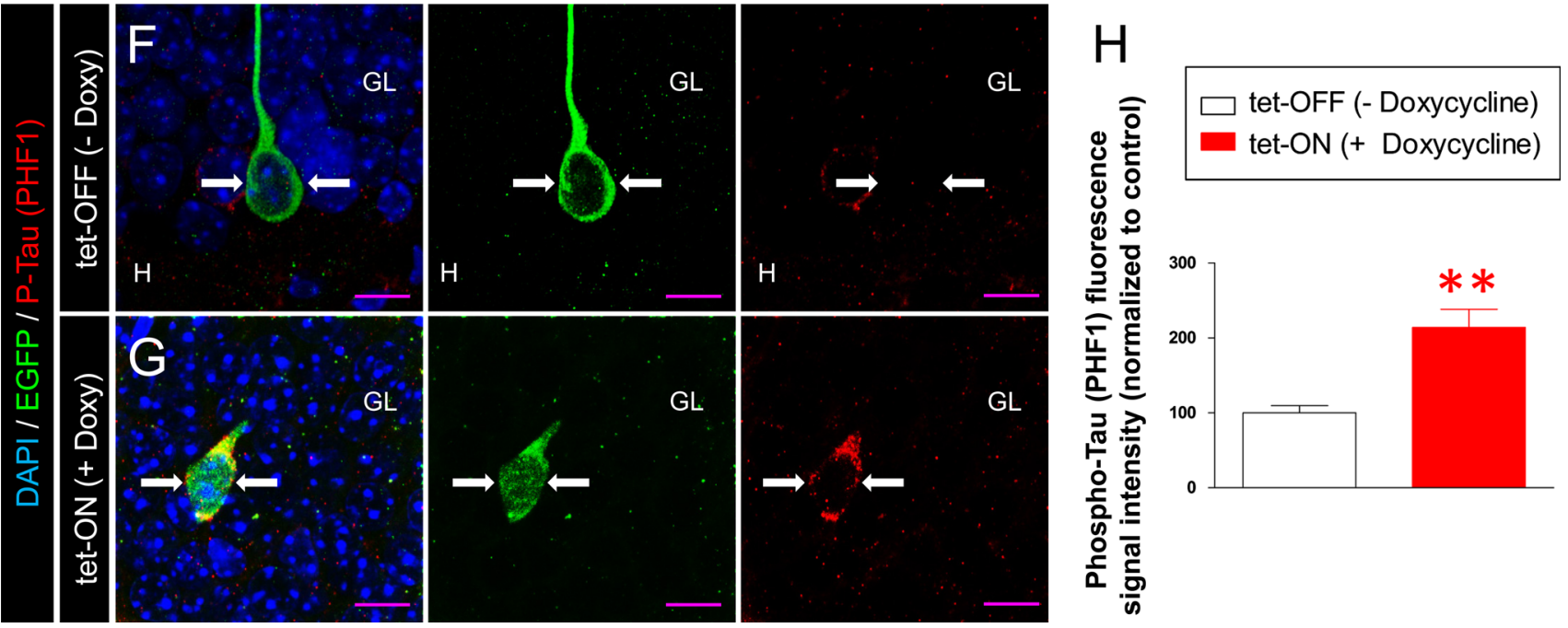
4Fig. 1 Description of the model. a Schematic diagram showing the most relevant elements in the plasmid used for retroviral production. The rtTA-IRES-EGFP was purchased from AddGene (reference number PMA2640). This plasmid permits the selective expression of the advanced rtTA element and EGFP as a reporter due to the presence of a rtTA-IRES-EGFP element. b The general basis of the experiments is shown. In tTO-GSK-3 $\beta$ mice, the expression of GSK$3 \beta$ takes place after the binding of the active rtTA element to the tetO bidirectional promoter. The rtTA element will undergo a conformational change and thus become activated by the presence of doxycycline. Upon activation, the rtTA element will allow the expression of both GSK-3 $\beta$ and $\beta$-galactosidase ( $\beta$-Gal) in targeted cells. c, $\mathbf{d}$ Representative images and their corresponding high-power magnification and orthogonal views showing the staining against $\beta$ $\mathrm{Gal} 48 \mathrm{~h}$ after retrovirus injection. As shown in $\mathbf{c}$, in tet-OFF mice (no doxycycline treatment), no $\beta$-Gal expression was detected in $\mathrm{EGFP}^{+}$ cells. In contrast, in tet-ON mice treated during $48 \mathrm{~h}$ after retrovirus injection with doxycycline, a strong and selective induction of the reporter protein was observed (d). e Quantification of the percentage of $\mathrm{EGFP}^{+}$cells that were also $\beta-\mathrm{Gal}^{+}$(time course). The percentage of $\mathrm{EGFP}^{+}$cells that were $\beta-\mathrm{Gal}^{+}$cells rapidly increased as the postinjection interval increased until reaching a plateau at $48 \mathrm{~h}$ postinjection. $\mathbf{f}-\mathbf{h}$ To obtain a physiological indicator of GSK-3 $\beta$ activity in infected newborn neurons, phosphorylated (PHF-1 epitopes) Tau (one of the main substrates of GSK-3 $\beta$ activity) was measured in individual $\mathrm{EGFP}^{+}$cells. f-g Representative images of EGFP and PHF-1 immunohistochemistry in tet-OFF (f) and tet-ON (g) mice. As shown, the fluorescence intensity of PHF-1 phospho-Tau was significantly increased in the tet-ON as compared to tet-OFF mice (h). $M L$ molecular layer, $G L$ granule layer, $H$ hilus. Yellow scale bar $20 \mu \mathrm{m}$, purple scale bar $10 \mu \mathrm{m}$, purple triangle $\mathrm{EGFP}^{+} \beta$-galactosidase $^{-}$cell, yellow triangle $\mathrm{EGFP}^{+} \beta$-galactosidase ${ }^{+}$cell, white arrows $\mathrm{EGFP}^{+}$cell. Asterisks indicate significant differences compared to tet-OFF mice $(* * 0.001<p<0.01)(* * * p<0.001)$

kind gift from Dr. Davies; 1:500). The following secondary Alexa-conjugated antibodies, from Molecular Probes (Carlsbad, CA, USA), were also used at a final concentration of 1:1000 to detect the primary antibodies: Donkey Alexa 488-conjugated anti rabbit (GFP); Donkey Alexa 555 -conjugated anti mouse ( $\beta$-galactosidase and PHF-1); Donkey Alexa 647-conjugated anti goat (DCX). All sections were counterstained with DAPI (Calbiochem; 1:5000). The incubation period ranged from $48 \mathrm{~h}$ at $4{ }^{\circ} \mathrm{C}$ for primary antibodies, $24 \mathrm{~h}$ at $4{ }^{\circ} \mathrm{C}$ for secondary antibodies, and $10 \mathrm{~min}$ for DAPI incubation.

\section{Cell counting}

The percentage of $\mathrm{EGFP}^{+}$cells that were also $\beta-\mathrm{Gal}^{+}$was assessed at 0,24 and $48 \mathrm{~h}$, and 1 week after retroviral injections in tet-OFF and tet-ON mice. A minimum of 250 $\mathrm{EGFP}^{+}$cells belonging to each experimental group and time point were analyzed. Two series of sections per animal were used to determine the percentage of $\mathrm{EGFP}^{+}$cells that were positive for $\beta$-Gal. To evaluate the staining of $\beta$-Gal in individual cells, each $\mathrm{EGFP}^{+}$cell was identified under the confocal microscope (green channel), and confocal stacks of images covering each whole cell (green channel: EGFP; Red channel: $\beta$-Gal) were obtained using a LSM710 Zeiss confocal microscope $(63 \times$ oil immersion objective). The percentage of $\mathrm{EGFP}^{+}$cells that were also $\beta-\mathrm{Gal}^{+}$is shown in Fig. 1 .

To analyze the phenotype of the cells infected by the rtTA-IRES-EGFP retrovirus and to compare it with that of cells infected by a CAG-GFP-expressing retrovirus [2], we quantified the percentage of cells either $\mathrm{GFP}^{+}$or $\mathrm{EGFP}^{+}$ that expressed the neuroblast marker DCX and GFAP at 1 week post-injection, and the mature neuronal marker NeuN and DCX at 4 weeks post-injection. To this end, at least 250 cells per experimental group and time point were examined. The percentage of cells is shown in Supplementary Figure S1 A (1 week post-injection) and B (4 weeks post-injection).

In addition, we addressed whether GSK-3 $\beta$ overexpression affected the generation of newborn neurons. To this end, we analyzed the phenotype of $\mathrm{EGFP}^{+}$cells in both tet-OFF and tet-ON conditions 4 weeks after rtTAIRES-EGFP retrovirus injection in the hippocampus of tTO-GSK-3 $\beta$ mice. We quantified the percentage of $\mathrm{EGFP}^{+}$cells that expressed NeuN ${ }^{+}$and $\mathrm{DCX}^{+}$(Supplementary Figure S1 C).

\section{Measurement of phospho-Tau in $\mathrm{EGFP}^{+}$cells}

To obtain a measurement of GSK-3 $\beta$ activity in the EGFP ${ }^{+}$ cells infected by the retrovirus, Tau phosphorylation (PHF1 epitope, known to be phosphorylated by GSK-3 $\beta$ ) was determined. With this aim, a minimum of 100 cells per experimental condition were analyzed. Cells were reconstructed using a LSM710 Zeiss confocal microscope $(63 \times$ Oil immersion objective; $x y$ dimensions $74.97 \mu \mathrm{m} ; z$ axis interval $0.2 \mu \mathrm{m})$. Confocal stacks of images containing blue (DAPI), green (EGFP), and red (PHF-1) channels were obtained. In each individual plane, the cytoplasm of the cell was drawn in the green channel using a pen tablet in ImageJ, and the area of the cytoplasm was measured in the green channel. Nuclei were excluded on the basis of the blue channel. Afterwards, by setting up threshold levels of 57 and 255 respectively, the intensity of PHF-1 staining was obtained in the red channel. Measurements were made in each individual plane. An average of phospho-Tau signal intensity per cell was subsequently calculated (Fig. 1f-h).

\section{Morphometric analysis}

Five series of sections from each animal were used for the immunohistochemical detection of EGFP. Sixty randomly selected neurons from each experimental condition were reconstructed under a LSM710 Zeiss confocal microscope $(25 \times$ oil immersion objective) as previously described 
[18]. Confocal stacks of images were obtained ( $z$ axis interval $1 \mu \mathrm{m}$ ) and $z$-projections were analyzed to determine total dendritic length and to perform Sholl's analysis [27]. All cells were traced using NeuronJ plugin for ImageJ software (ImageJ v.1.45S, http://rsb.info.nih.gov/ij/). Sholl's analysis was performed using the plugin ShollAnalysis for ImageJ. The analysis of the morphology of newborn neurons is shown in Fig. 2.

\section{Analysis of dendritic spines}

The analysis of dendritic spines is shown in Fig. 3. The density of dendritic spines was studied in each experimental condition. A minimum of 100 segments belonging to each condition were analyzed. Confocal stacks of images were obtained in a LSM710 Zeiss confocal microscope $(63 \times$ oil immersion objective, $x y$ dimensions $67.48 \mu \mathrm{m})$ ( $z$ axis interval $0.1 \mu \mathrm{m}$ ). The dendritic length of each segment was measured, and the number of dendritic spines was analyzed using the NeuronStudio software (CNIC, Mount Sinai School of Medicine, 2007-2009) [28]. Dendritic fragments were automatically constructed by the software, and then individual seed points were rectified manually to more accurately trace the dendrite. Thereafter, the dendritic spines were detected by the software and assigned to one of the three following subtypes: stubby, thin, and mushroom. The following parameters used by NeuronStudio software were applied to identify three spine subtypes: neck ratio, 1.1 pixel; thin ratio, 2.5 pixel; mushroom size, $0.35 \mu \mathrm{m}$. A manual check of each spine was performed to assure accurate classification. The percentage of each type of spine was calculated. The percentage of mushroom spines is shown in Fig. 3f. Given that the volume of the head of mushroom spines correlates with the size of the postsynaptic density, which in turn is correlated with synaptic strength [29], we measured the head diameter of the mushroom spines (Fig. 3g).

\section{Statistical analysis}

Statistical analysis was performed using the SPSS 17.0.1 software (SPSS, 1989; Apache Software Foundation). The Kolmogorov-Smirnov test was used to test the normality of the sample distribution. Quantitative variables (levels of phosphorylated Tau, total dendritic length, dendritic arborization (Sholl's analysis), length of the primary apical dendrite, migration into the granule cell layer (GL), density of dendritic spines, percentage of mushroom spines and head diameter of mushroom spines) were analyzed by a one-way ANOVA test. For the comparison of qualitative variables (percentage of $\mathrm{EGFP}^{+}$cells that were positive for either $\beta$-Gal, DCX, GFAP or NeuN), a Pearson Chi squared test was applied. Post-hoc analyses were done using a
Fig. 2 Retroviral expression of GSK-3 $\beta$ causes morphological alterations in newborn neurons. In a, the complete experimental design is presented. Retroviruses were injected into the hippocampus of tTOGSK-3 $\beta$ mice. Two weeks after injection, mice were assigned to one of the four experimental categories: sedentary tet-OFF, sedentary tet$\mathrm{ON}$, exercise tet-OFF, or exercise tet-ON. b Quantification of the total dendritic length. It should be noted that GSK-3 $\beta$ activity caused a significant reduction in the total dendritic length of newborn neurons. In contrast, physical exercise increased this parameter in exercise tetOFF mice. Interestingly, physical activity partially reversed the alterations caused by GSK-3 $\beta$ overexpression. However, significant differences were observed between exercise tet-OFF and exercise tetON mice. $\mathbf{c}$ Sholl's analysis. GSK-3 $\beta$ activity caused alterations in the morphology of the dendritic tree of sedentary tet-ON mice. Physical exercise increased dendritic branching in exercise tet-OFF mice and normalized morphological alterations in exercise tet-ON mice. dg Representative images of the cellular morphology of newborn neurons in sedentary tet-OFF (d), sedentary tet-ON (e), exercise tet$\mathrm{OFF}(\mathbf{f})$, and exercise tet-ON (g) mice. h Quantification of the length of the primary apical dendrite. GSK- $3 \beta$ overexpression decreased this parameter in sedentary tet-ON mice, whereas physical exercise caused an increase in sedentary tet-OFF mice and normalized the alterations in exercise tet-ON mice. i Migration into the GL. GSK-3 $\beta$ increased the distance migrated by newborn neurons in sedentary tet$\mathrm{ON}$ mice. Exercise reversed these alterations in exercise tet-ON mice. $M L$ molecular layer, $G L$ granule layer, $H$ hilus. Blue scale bar $100 \mu \mathrm{m}$. Asterisks indicate significant differences compared to sedentary tet-OFF mice. Hashes indicate significant differences compared to sedentary tet-ON mice $(* 0.01<p<0.05)$ $(* * 0.001<p<0.01) \quad(* * * p<0.001) \quad\left({ }^{\#} 0.01<\quad p<0.05\right)$ $\left({ }^{\# \#} 0.001<p<0.01\right)\left({ }^{\# \# \#} p<0.001\right)(! 0.1>p>0.05)$

Fisher's least significant difference (LSD) test. In all the figures, mean \pm SEM are represented.

\section{Results}

\section{rtTA-expressing retrovirus as a tool to induce GSK- $3 \beta$ overexpression in newborn neurons}

These experiments involved the use of a retrovirus containing the rtTA, IRES and EGFP elements and the stereotaxic injection of this retrovirus into the hippocampus of tTO-GSK-3 $\beta$ mice to selectively induce GSK-3 $\beta$ overexpression in newborn granule neurons. To study the activation of the system along time, we stereotaxically injected the retroviral vectors into the hippocampus of 8 -week-old tTO-GSK-3 $\beta$ mice and killed the animals 1,2 , or 7 days later (Fig. 1c-e). A control group of five mice were killed just before the retroviral injection (time 0 ) (12 $\mathrm{h}$ after the beginning of doxycycline treatment). Given the lack of specificity previously obtained with numerous antibodies against GSK-3 $\beta$ in murine tissue (data not shown), it was not possible to evaluate the level of GSK-3 $\beta$ overexpression in the infected cells by immunohistochemical labeling of GSK-3 $\beta$ directly. However, we have 

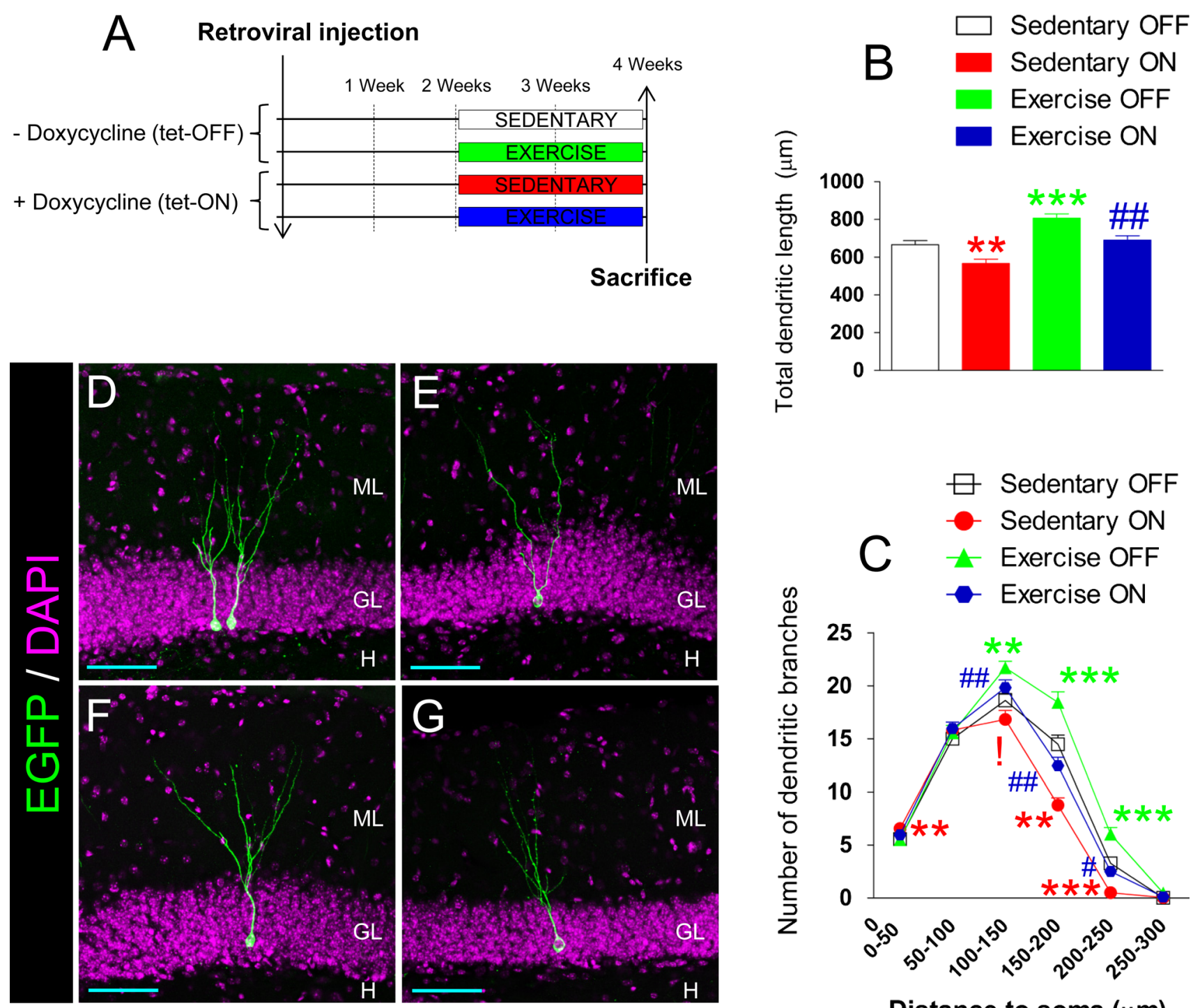

\section{Distance to soma $(\mu \mathrm{m})$}

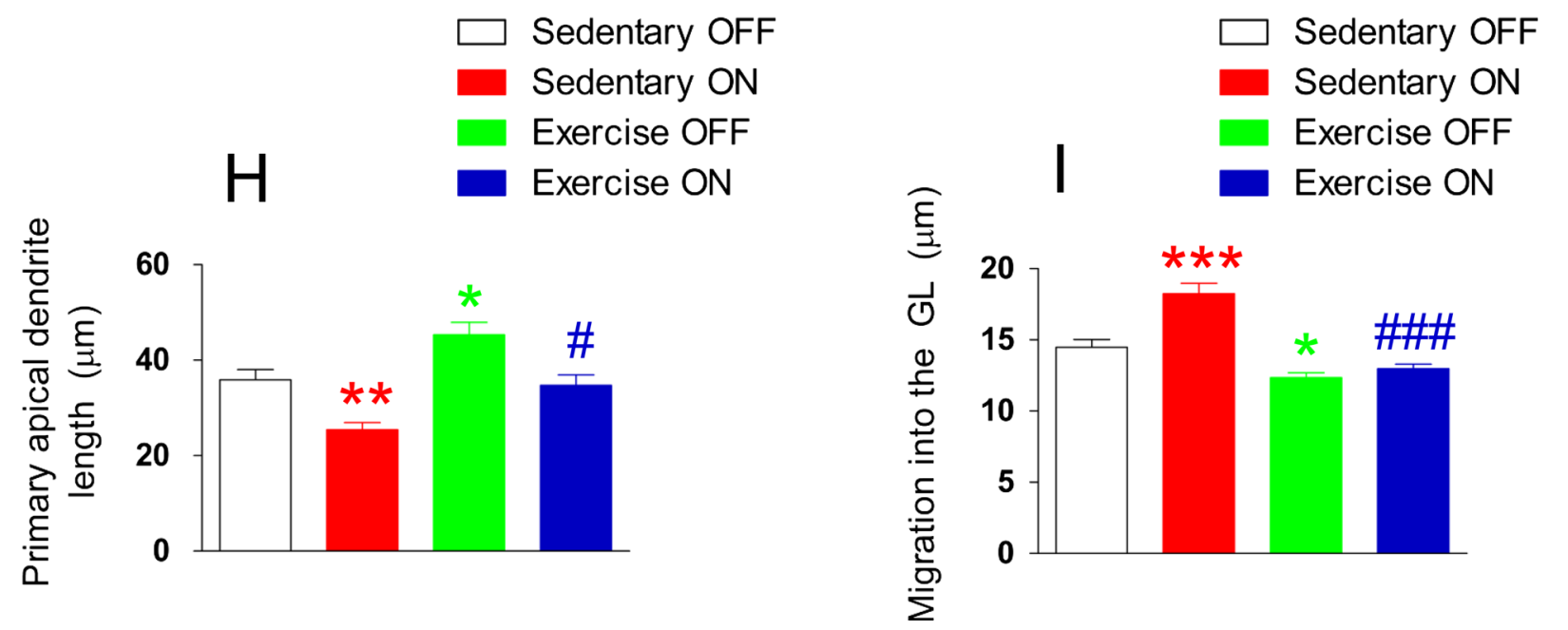


previously demonstrated that the immunohistochemical detection of the reporter protein $\beta$-Gal matches that of GSK- $3 \beta$ perfectly in GSK- $3 \beta$ overexpressing mice $[18,22$, $30]$. Hence, we aimed to analyze the levels of $\beta-G a l$ in $\mathrm{EGFP}^{+}$cells at the different cell ages studied. A rapid induction of GSK-3 $\beta$ overexpression was observed after retrovirus injection in the presence of Doxycycline (tet-ON animals). At $24 \mathrm{~h}$ after retroviral injection, $52.94 \%$ of the $\mathrm{EGFP}^{+}$cells were also $\beta-\mathrm{Gal}^{+} \quad\left(\chi^{2}{ }_{1,64}=28.954\right.$; $p<0.001)$, while $94.68 \%$ cells $\quad\left(\chi_{1,141}^{2}=120.663\right.$; $p<0.001)$ and $97.18 \%$ of the cells $\left(\chi_{1,118}^{2}=109.995\right.$; $p<0.001)$ were $\beta-\mathrm{Gal}^{+}$at $48 \mathrm{~h}$ and 1 week post-injection respectively in the presence of doxycycline. Conversely, less than $0.6 \%$ of $\mathrm{EGFP}^{+} \beta-\mathrm{Gal}^{+}$cells were observed in the absence of Doxycycline treatment. In Fig. 1c, a representative cell belonging to the tet-OFF group is shown. Forty-eight hours after the retroviral injection, no staining for $\beta$-Gal was observed in the absence of doxycycline. However, in the doxycycline-treated group, $\mathrm{EGFP}^{+}$cells exhibited marked immunoreactivity for $\beta$-Gal (Fig. 1d). The complete quantification of this time course is shown in Fig. 1e.

Moreover, to demonstrate that this retroviral system caused an effective increase of GSK-3 $\beta$ activity in the cells infected by the retrovirus, we aimed to obtain a biological indicator of GSK-3 $\beta$ activity in these cells. To this end, we measured the levels of Tau phosphorylation (PHF-1 epitopes) in individual $\mathrm{EGFP}^{+}$cells 4 weeks after retroviral injections (Fig. 1f-h). Hyperphosphorylation of Tau in PHF-1 epitopes is known to reduce Tau affinity to microtubules and to trigger cytoskeleton destabilization [31]. Figure 1f, g shows representative images of the colocalization of EGFP and PHF-1 in tet-OFF (Fig. 1f) and tet-ON (Fig. 1g) mice. The retroviral infection resulted in increased Tau phosphorylation in PHF1 epitopes (known to be phosphorylated by GSK-3 $\beta$ ), thus indicating and increase in GSK-3 $\beta$ activity in tet-ON cells. Figure $1 \mathrm{~h}$ shows the quantification of fluorescence intensity for PHF1 in individual $\mathrm{EGFP}^{+}$cells. The Tet-ON cells presented greater levels of phosphorylated Tau than tet-OFF cells $\left(F_{1,350}=79.390 ; p<0.001\right)$.

Given that, to the best of our knowledge, this retroviral construct has not been used in the context of AHN to date, we sought to characterize the populations of cells infected by the retrovirus, to compare these data with those obtained using a CAG-GFP-expressing retrovirus [2]. The quantification of $\mathrm{EGFP}^{+}$cell phenotypes at 1 and 4 weeks postinjection is shown in Supplementary Figure S1 A and B, respectively. At 1 week post-infection, 56.8 and $65 \%$ of the cells were $\mathrm{DCX}^{+}$, whereas 10 and $4 \%$ were $\mathrm{GFAP}^{+}$in the case of cells infected by GFP-expressing and rtTAIRES-EGFP-expressing retroviruses, respectively, these differences falling far from statistical significance. In addition, 4 weeks after retroviral injections, 97 and $92.3 \%$ of the cells were $\mathrm{NeuN}^{+}$, whereas 91 and the $89.4 \%$ were $\mathrm{DCX}^{+}$in the case of cells infected by GFP-expressing and rtTA-IRES-EGFP-expressing retroviruses, respectively. These data demonstrate that, 4 weeks after retroviral injections, roughly $99 \%$ of the cells infected by rtTAIRES-EGFP were newborn neurons.

In addition, and given that GSK-3 $\beta$ overexpression has previously been demonstrated to inhibit the generation of newborn neurons $[32,33]$, we analyzed the percentage of cells infected by the retrovirus that expressed NeuN and DCX markers at 4 weeks post-injection, in both the tet-ON and tet-OFF conditions. This quantification is shown in Supplementary Figure S3 C. In this regard, 92.31 and $92.08 \%$ of the $\mathrm{EGFP}^{+}$cells were $\mathrm{NeuN}^{+}$, whereas 89.42 and $87.13 \%$ of the $\mathrm{EGFP}^{+}$cells were $\mathrm{DCX}^{+}$in tet-OFF and tet-ON conditions, respectively. These data demonstrate that this retroviral system of GSK-3 $\beta$ overexpression does not alter the generation of newborn neurons in terms of their number and phenotype.

\section{GSK-3 $\beta$ overexpression prevents the stimulatory effects of physical exercise on the morphological maturation of newborn neurons}

Figure 2a shows a schematic diagram of the experimental design. The rtTA-IRES-EGFP retroviruses were stereotaxically injected into the hippocampus of tTO-GSK-3 $\beta$ mice. Two weeks after these injections, half the animals were allowed to use voluntary running wheels freely for two additional weeks, thus becoming assigned to one of the following conditions: sedentary tet-OFF, sedentary tet-ON, exercise tet-OFF, or exercise tet-ON. Four weeks after injections, mice were killed and the morphology of the newborn granule neurons was analyzed. The four experimental conditions presented differences in total dendritic length $\left(F_{3,238}=18.978 ; p<0.001\right)$. GSK-3 $\beta$ overexpression in these cells caused a reduction in total dendritic length in sedentary tet-ON as compared to sedentary tetOFF mice $(p<0.05)$ (Fig. 2b). In contrast, physical exercise increased total dendritic length in comparison to tetOFF sedentary mice $(p<0.001)$. In addition, exercise reversed the alterations caused by GSK- $3 \beta$ overexpression, and the exercise tet-ON mice were indistinguishable from sedentary tet-OFF ones $(p=0.882)$. There was a significant difference in total dendritic length between exercise tet-OFF and exercise tet-ON mice $(p<0.01)$. Sholl's analysis revealed that GSK-3 $\beta$ overexpression altered the branching and structure of the dendritic tree (Fig. 2c) $\left[0-50 \mu \mathrm{m}\right.$ from the soma: $\left(F_{3,234}=3.513 ; p<0.05\right)$; $50-100 \mu \mathrm{m}$ from the soma: $\left(F_{3,239}=0.46 ; p=0.710\right)$; $100-150 \mu \mathrm{m}$ from the soma: $\left(F_{3,238}=7.523 ; p<0.001\right)$; $150-200 \mu \mathrm{m}$ from the soma: $\left(F_{3,239}=21.859 ; p<0.001\right)$; 

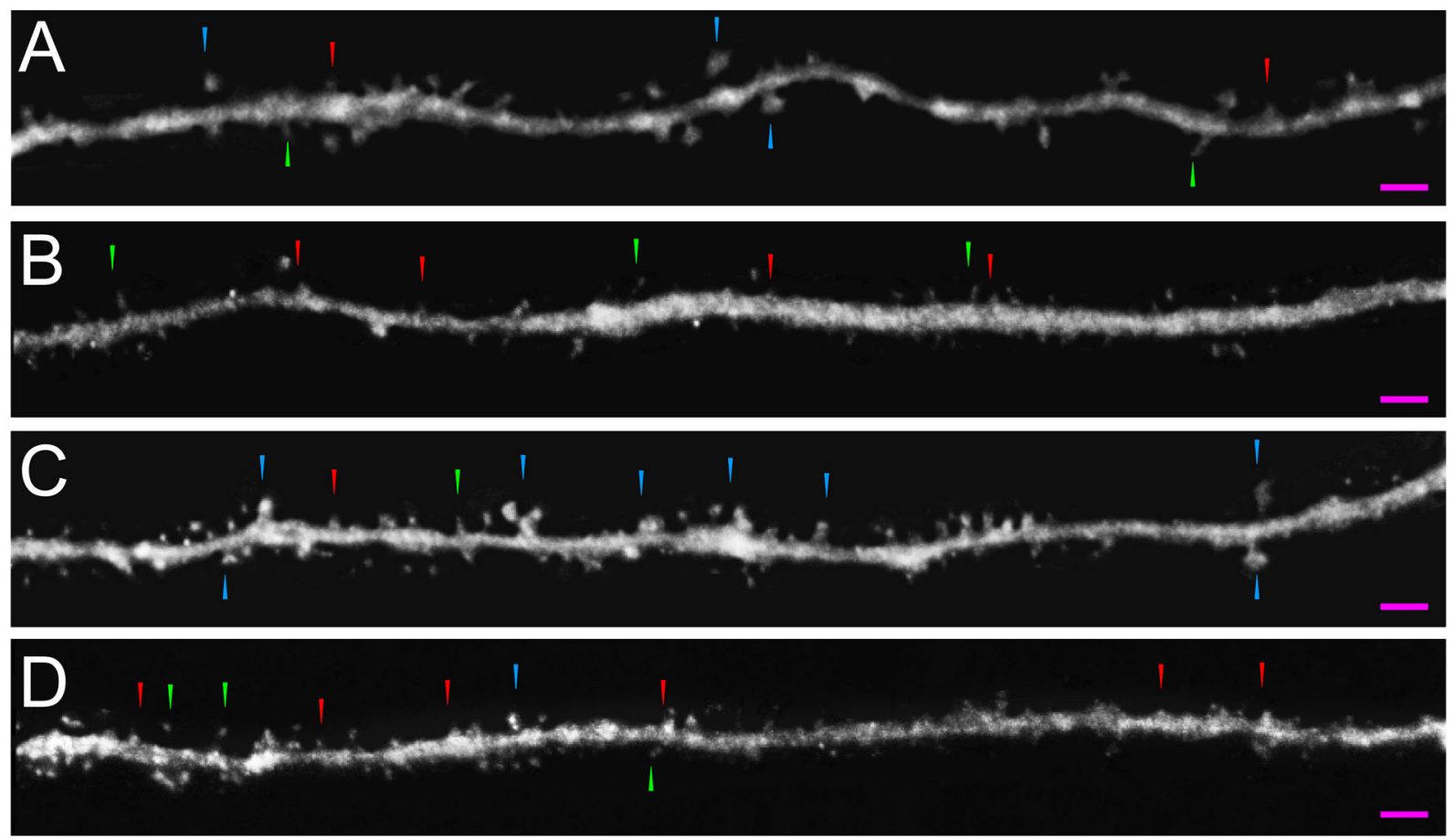
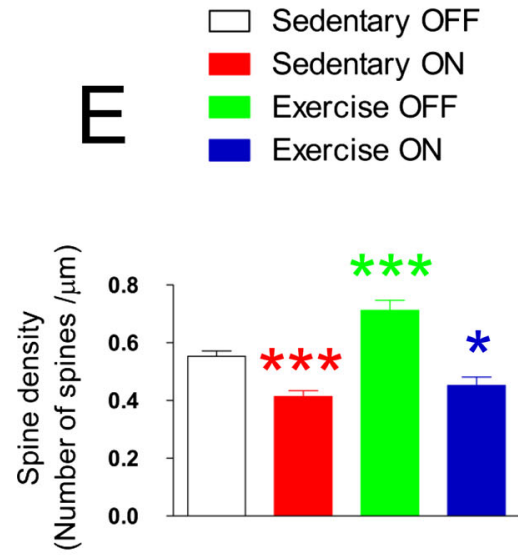
Sedentary OFF
Sedentary ON
Exercise OFF
Exercise ON

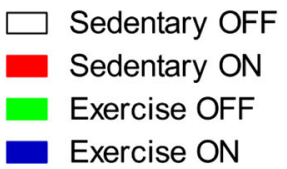

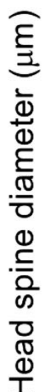

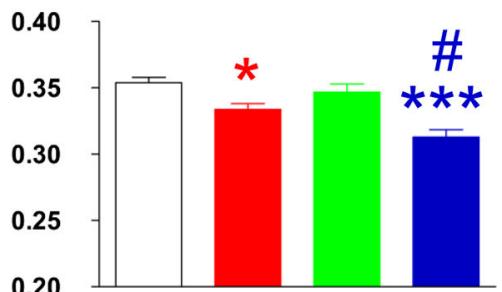

Fig. 3 Retroviral expression of GSK-3 $\beta$ alters the connectivity of newborn neurons. a-d Representative images of fragments of dendrites belonging to sedentary tet-OFF (a), sedentary tet-ON (b), exercise tet-OFF (c), and exercise tet-ON (d) mice. e Quantification of dendritic spine density. As shown, retroviral induction of GSK-3 $\beta$ activity decreased the density of dendritic spines. In contrast, physical exercise increased the density of these structures in exercise tet-OFF mice. Importantly, exercise did not cause any change in the density of dendritic spines in exercise tet-ON as compared to sedentary tet-ON mice. $\mathbf{f}$ Percentage of mushroom spines. Retroviral induction of GSK$3 \beta$ activity reduced the percentage of mushroom spines. Exercise did not counteract these effects in exercise tet-ON mice, but increased the percentage in exercise tet-OFF mice. $\mathrm{g}$ Head diameter in the mushroom spines. Retroviral induction of GSK-3 $\beta$ activity reduced the head diameter in sedentary tet-ON mice. This effect was further accentuated in exercise tet-ON mice. Taken together, these data demonstrate that the retroviral induction of GSK-3 $\beta$ activity prevents the stimulatory effects of physical exercise on newborn neurons. Purple scale bar $100 \mu \mathrm{m}$, blue triangles mushroom spines, red triangles stubby spines, green triangles thin spines. Asterisks indicate significant differences compared to sedentary tet-OFF mice. Hashes indicate significant differences compared to sedentary tet-ON mice $(* 0.01<p<0.05)(* * * p<0.001)\left({ }^{\#} 0.01<p<0.05\right)$

$p=0.556) ; 100-150 \mu \mathrm{m}$ from the soma: $\left(F_{1,238}=16.264\right.$; $p<0.001)$; 150-200 $\mu \mathrm{m}$ from the soma: $\left(F_{1,239}=19.193\right.$; $p<0.001)$; and $200-250 \mu \mathrm{m}$ from the soma: $\left(F_{1,223}=\right.$ $0.639 ; p=0.425)]$. However, exercise tet-OFF and exercise tet-ON mice showed statistically significant
200-250 $\mu \mathrm{m}$ from the soma: $\left.\left(F_{3,223}=24.023 ; p<0.001\right)\right]$. Physical exercise stimulated the growth of the medialto-distal region of the dendritic tree in both tet-OFF and tet-ON mice [0-50 $\mu \mathrm{m}$ from the soma: $\left(F_{1,234}=0.962\right.$; $p=0.328)$; 50-100 $\mu \mathrm{m}$ from the soma: $\left(F_{1,239}=0.347\right.$; 
differences in the distal part of the dendritic tree $[0-50 \mu \mathrm{m}$ from the soma: $(p=0.256) ; 50-100 \mu \mathrm{m}$ from the soma: $(p=0.659)$; $100-150 \mu \mathrm{m}$ from the soma: $(p=0.084)$; $150-200 \mu \mathrm{m}$ from the soma: $(p<0.001)$; and $200-250 \mu \mathrm{m}$ from the soma: $(p<0.001)]$. In Fig. $2 \mathrm{~d}-\mathrm{g}$, representative images of neurons belonging to each of the four experimental conditions are shown: sedentary tet-OFF (Fig. 2d), sedentary tet-ON (Fig. 2e), exercise tet-OFF (Fig. 2f) and exercise tet-ON (Fig. 2g). In line with the aforementioned morphological changes, GSK-3 $\beta$ overexpression reduced the length of the primary apical dendrite $\left(F_{1,323}=23.352 ; \quad p<0.001\right) \quad($ Fig. $2 \mathrm{~h})$ and increased migration into the GL $\left(F_{1,268}=17.204 ; p<0.001\right)$ (Fig. 2i). The stimulatory effect of physical exercise on these two parameters occurred only partially in exercise tet-ON as compared to exercise tet-OFF mice (length of the primary apical dendrite, $p=0.003$; migration into the $\mathrm{GL}, p=0.834)$.

\section{GSK-3 $\beta$ overexpression prevents the stimulatory action of physical exercise on the connectivity of newborn neurons}

To examine whether the effects of physical exercise on the connectivity of newborn neurons is blocked by GSK$3 \beta$, the four experimental conditions were compared in terms of the number, morphological classification, and size of their dendritic spines. In Fig. 3a-d, representative images of dendrite fragments belonging to sedentary tetOFF (Fig. 3a), sedentary tet-ON (Fig. 3b), exercise tetOFF (Fig. 3c), and exercise tet-ON (Fig. 3d) groups are shown. Quantifications revealed that GSK-3 $\beta$ decreased the density of dendritic spines $\left(F_{1,275}=61.165\right.$; $p<0.001$ ) (Fig. 3e), the percentage of mushroom spines $\left(F_{1,272}=67.158 ; p<0.001\right)$ (Fig. 3f), and the diameter of the head of the mushroom spine $\left(F_{1,261}=28.071\right.$; $p<0.001$ ) (Fig. 3g). In contrast, physical exercise increased the density of dendritic spines $(p<0.001)$ (Fig. 3e) and the percentage of mushroom spines $(p<0.001)$ (Fig. 3f) in exercise tet-OFF mice. However, exercise had no effect on the density of dendritic spines ( $p=0.747$ ) (Fig. 3e) or the percentage of mushroom spines $(p=0.304)$ (Fig. 3f) in exercise tet-ON mice as compared to sedentary tet-ON ones. In addition, it further reduced the diameter of the head of the mushroom spine as compared to the latter group $(p<0.01)$ (Fig. $3 \mathrm{~g}$ ). These data thus suggest that the stimulatory action exerted by physical activity on the connectivity of newborn granule neurons is blocked by GSK-3 $\beta$ overexpression.

\section{Discussion}

\section{Physiological and pathological regulation of AHN: importance of GSK-3 $\beta$}

New neurons are continuously added to the hippocampal DG throughout adulthood [34]. During the differentiation of newborn neurons, the complexity of their dendritic trees increases sequentially. After the appearance of dendritic spines, the number, volume and complexity of these structures increase until reaching a plateau at 8-10 weeks of cell age [35]. Growing evidence indicates that newborn neurons are important for hippocampal function, not only when they are mature but also during the transient period in which they are young and excitable [36]. In general terms, it is considered that immature neurons are required for pattern separation [37], whereas mature ones are necessary for pattern completion [38]. Nevertheless, the involvement of AHN in learning is still a matter of debate and the specific role of newborn neurons in hippocampal-dependent learning has yet to be fully elucidated $[16,39]$.

In neurodegenerative diseases, such as $\mathrm{AD}$, the generation of functional neurons in the DG is impaired. This observation has been made both in animal models [40, 41] and $\mathrm{AD}$ patients [42]. In this regard, Golgi staining has revealed morphological and synaptic alterations of granule neurons in $\mathrm{AD}$ patients. These alterations are identical to those found in GSK-3 $\beta$-overexpressing mice, a murine model of AD [18]. These alterations include a shortening of the primary apical dendrite, increased migration into the GL, and atrophy of the distal portions of the dendritic tree.

In these mice, the overexpression of GSK-3 $\beta$ occurs in mature granule neurons under the control of the neuronal promoter CamKII [22]. These findings are especially relevant since a pathological overactivation of this kinase has been reported in the brains of AD patients [43]. In fact, it is known that GSK-3 $\beta$ activation is necessary for amyloid $\beta$ $(\mathrm{A} \beta)$ to exert its toxic action [44]. It is considered that one of the most important downstream effectors of GSK-3 $\beta$ activity is the microtubule-associated protein Tau [45]. Tau phosphorylation by GSK-3 $\beta$ is thought to be responsible for the memory impairment found in $\mathrm{AD}$ [46]. At the molecular level, GSK-3 $\beta$ has a deleterious effect on neuron connectivity and it has been implicated in the internalization of AMPA receptors. This process has been linked to the elimination of the synapse [47], a process in which, on the other hand, Tau is involved via the abnormal cellular distribution of Fyn kinase [48]. Thus, Tau-dependent and -independent actions of GSK-3 $\beta$ converge in a profound impairment of neuronal function. These alterations are a priori assumed to be a direct cell-autonomous consequence of GSK-3 $\beta$ action. 
However, we and others have demonstrated that GSK$3 \beta$, when overexpressed in a wide population of cells, causes a series of indirect, non-cell-autonomous effects linked to neuroinflammation [19, 49]. These alterations related to neuroinflammation occur in the murine model previously described, as a result of microglial activation caused by neuron death [18]. However, the administration of an anti-inflammatory drug does not fully reverse the alterations observed in this animal model [19]. Hence, there must be a unique action that can be attributed only to GSK-3 $\beta$. This notion led us to design a model to induce GSK-3 $\beta$ overexpression exclusively in the cells of interest, to avoid the indirect effects caused by microglial activation.

\section{Development of a novel methodology to study the cell-autonomous effects of GSK-3及}

With this aim, we stereotaxically injected an rtTA-IRESEGFP-expressing retrovirus into the hippocampi of tTOGSK-3 $\beta$ mice (Fig. 1b). To the best of our knowledge, this is the first time that this retroviral strategy has been used to drive the expression of a toxic protein involved in $\mathrm{AD}$ in the brain and, in particular, to study AHN. Using this retroviral tool, we have developed an extremely reliable method to selectively induce the conditional expression of GSK-3 $\beta$ exclusively in the newborn neurons infected by the retrovirus and only after the binding of the active rtTA element to the tetO promoter in the presence of doxycycline (Fig. 1c-e). Using this system, we demonstrated a measurable increase in the activity of GSK-3 $\beta$ in the cells infected by the retrovirus through quantification of phosphorylated Tau, the main substrate of GSK-3 $\beta$, in epitopes known to be phosphorylated by this serine-threonine kinase (Fig. 1f-h). This increased activity of GSK-3 $\beta$ triggered a profound impairment not only in the morphological but also in synaptic maturation of these cells. Regarding the morphological changes triggered by cellautonomous GSK-3 $\beta$ overexpression, it is noteworthy that GSK-3 $\beta$ reduced the total length of the dendritic trees of these cells (Fig. 2b); however, importantly, it caused a selective atrophy of the outer part of the dendritic tree (Fig. 2c-g). In addition, it shortened the primary apical dendrite (Fig. 2h) and increased cell soma migration into the GL (Fig. 2i). These morphological alterations may have important functional consequences, given that the most relevant afferent connections received by the dendrites of granule neurons occur in the two outer thirds of the molecular layer (ML) through the performant pathway, which is originated in the entorhinal cortex $[50,51]$.

\section{AD therapies: relevance of GSK-3 $\beta$ and physical exercise}

Several hypotheses regarding the dysregulation of GSK-3 $\beta$ activity in the brains of AD patients have been put forward. One, the "neurotrophic hypothesis of AD", postulates that the decrease in the circulating levels of neurotrophic factors during aging contributes to the dysregulation of GSK$3 \beta$ activity $[52,53]$. For instance, it is known that insulinlike growth factor I (IGF-I) participates in A $\beta$ clearance from the brain [54]. As a result of the decrease in this clearance, $A \beta$ would trigger, in turn, the pathological activation of GSK-3 $\beta$ [44]. On the other hand, brain inflammation has also been proposed to induce the initial changes occurring in the $\mathrm{AD}$ brain in the prodromal stages of the disease. These inflammatory changes have been demonstrated to induce Tau phosphorylation, presumably through an increase in GSK-3 $\beta$ activity [55]. Therefore, diverse mechanisms have been proposed to increase the activity of this kinase, which leads to the aberrant phosphorylation of Tau, thereby contributing to the cellular and cognitive alterations characteristic of $\mathrm{AD}$.

Although several general and specific inhibitors of GSK-3 $\beta$ have been tested for the treatment of AD [56], physical activity is thought to be useful for counteracting the pathological activation of GSK-3 $\beta$ [57]. Indeed, one of the most accepted theories on how exercise acts on the brain, the "neurotrophic hypothesis of physical exercise", affirms that one of the most potent neuroprotective actions triggered by exercise is by increasing the levels of different neurotrophic factors in the brain [58-62]. Since these factors converge in a consequent inhibition of GSK-3 $\beta$ activity, physical exercise might be useful to counteract the pathological dysregulation of this kinase. Furthermore, exercise increases hippocampal volume, memory, and cognitive skills both in animal models and humans [63, 64]. Importantly, the beneficial actions of exercise occur not only in the healthy brain but also in the AD brain [65, 66]. However, although it has been proposed that physical exercise protects against the development of $\mathrm{AD}$ [65], it remains unclear whether it is beneficial after the onset of the disease. Indeed, several studies suggest that exercise fails to increase neural plasticity in animal models and $\mathrm{AD}$ patients $[67,68]$. To demonstrate whether GSK-3 $\beta$ overexpression interferes with the stimulatory actions of physical exercise, we subjected the retrovirus-injected mice to a period of voluntary wheel running (Fig. 2a), an activity previously demonstrated to enhance AHN [26]. As expected, we found a prominent effect of exercise on control tet-OFF neurons (Figs. 2, 3). Both the morphology of the dendritic tree (Fig. 2b-i) and the number of dendritic spines and their degree of maturation (Fig. 3a-g) were 
markedly promoted by voluntary wheel running. Interestingly, exercise promoted the growth of the medial-to-distal portions of the dendritic tree (Fig. 2c), which are known to be projected towards the more external parts of the ML. As previously mentioned, the most relevant afferent connection establishing synaptic contacts with the dendrites of granule neurons (the performant pathway) occurs in the two outer thirds of the ML. Thus, these effects of physical exercise on the distal dendritic tree of newborn neurons may be related to its general stimulatory actions on the maturation of these cells, which might also be associated with changes in their connectivity. In contrast, although slight stimulatory effects of exercise were observed on the morphology of the dendritic tree, no effects were detected on the afferent connectivity of tet-ON, GSK-3 $\beta$-overexpressing neurons (Fig. 3e, f). In addition, a further reduction in the head diameter of mushroom spines was observed in exercise tet-ON neurons as compared with sedentary tet-OFF ones, the former already being diminished as compared to sedentary tet-OFF neurons (Fig. 3g). Thus, not only did physical exercise not cause improvements of the alterations caused by GSK-3 $\beta$ cellautonomous effects but it worsened some of them.

We demonstrate that GSK-3 $\beta$ overexpression limits the stimulatory effects of physical exercise on newborn granule neurons. These findings may be clinically relevant for $\mathrm{AD}$ therapies, as GSK-3 $\beta$ appears to determine the efficacy of physical exercise in the functional maturation of newborn granule neurons.

\section{Concluding remarks}

The novel methodology used in this work has allowed us to study the cell-autonomous effects of GSK-3 $\beta$ on newborn neurons. Here we demonstrate an increase in GSK-3 $\beta$ activity in retrovirally infected cells, as reflected the elevated levels of phosphorylated Tau. In addition, our data suggest that the efficacy of physical exercise at the cellular level, is, to some extent, regulated by the activity of GSK$3 \beta$ in newborn granule neurons. This notion is supported by the observation that exercise-triggered cellular plasticity is blocked by GSK-3 $\beta$ overexpression in these neurons. We show, on the one hand, that the dysregulation of the intracellular pathways controlled by GSK-3 $\beta$ sabotages newborn neuron maturation in a cell-autonomous manner, and, on the other hand, that physical exercise is unable to counteract these alterations in neurons affected by cellautonomous GSK-3 $\beta$ overexpression. Given that exercise is considered to exert beneficial effects on cognition and that GSK-3 $\beta$ activity is increased in the brains of individuals with $A D$, the lack of effects of physical exercise on GSK-3 $\beta$-overexpressing neurons may be relevant with regard to the non-pharmacological therapies for this disease. The rationale supporting this affirmation is that, among other reasons, physical exercise-due to its trophic effects on the hippocampus-could be potentially prescribed to ameliorate some of the pathological consequences of $\mathrm{AD}$. However, the finding that the dysregulation of GSK-3 $\beta$ activity limits the effectiveness of exercise on AHN may be relevant for these therapies, since this cell population in the AD brain may not be responsive to the effects of this physical stimulus.

Acknowledgments This study was funded by grants from the Spanish Ministry of Health (SAF-2014-5040-P), and the Centro de Investigación Biomédica en Red sobre Enfermedades Neurodegenerativas (CIBERNED, ISCIII) (J. Ávila); the Japan Society for the promotion of Science (post-doctoral fellowship to M. Llorens-Martín); and the Alzheimer's Association (2015-NIRG-340709) (M. Llorens-Martín). The authors thank E. García for help producing retroviral vectors and F. H. Gage for providing the plasmids used for the production of GFP-expressing retroviruses.

\section{Compliance with ethical standards}

Conflict of interest The authors declare no competing financial interest. This is an original manuscript that is not being considered for publication elsewhere.

\section{References}

1. Kempermann G, Kuhn HG, Gage FH (1998) Experience-induced neurogenesis in the senescent dentate gyrus. J Neurosci 18(9):3206-3212

2. Zhao C, Teng EM, Summers RG Jr, Ming GL, Gage FH (2006) Distinct morphological stages of dentate granule neuron maturation in the adult mouse hippocampus. J Neurosci 26(1):3-11. doi:10.1523/JNEUROSCI.3648-05.2006

3. Gould E, Tanapat P, Rydel T, Hastings N (2000) Regulation of hippocampal neurogenesis in adulthood. Biol Psychiatry 48(8):715-720

4. Gould E, Tanapat P (1999) Stress and hippocampal neurogenesis. Biol Psychiatry 46(11):1472-1479

5. Villeda SA, Luo J, Mosher KI, Zou B, Britschgi M, Bieri G, Stan TM, Fainberg N, Ding Z, Eggel A, Lucin KM, Czirr E, Park JS, Couillard-Despres S, Aigner L, Li G, Peskind ER, Kaye JA, Quinn JF, Galasko DR, Xie XS, Rando TA, Wyss-Coray T (2011) The ageing systemic milieu negatively regulates neurogenesis and cognitive function. Nature 477(7362):90-94. doi:10.1038/ nature 10357

6. Lazarov O, Marr RA (2010) Neurogenesis and Alzheimer's disease: at the crossroads. Exp Neurol 223(2):267-281. doi:10.1016/ j.expneurol.2009.08.009

7. Li B, Yamamori H, Tatebayashi Y, Shafit-Zagardo B, Tanimukai H, Chen S, Iqbal K, Grundke-Iqbal I (2008) Failure of neuronal maturation in Alzheimer disease dentate gyrus. J Neuropathol Exp Neurol 67(1):78-84. doi:10.1097/nen.0b013e318160c5db

8. van Praag H, Kempermann G, Gage FH (1999) Running increases cell proliferation and neurogenesis in the adult mouse dentate gyrus. Nat Neurosci 2(3):266-270. doi:10.1038/6368

9. Intlekofer KA, Cotman CW (2013) Exercise counteracts declining hippocampal function in aging and Alzheimer's disease. Neurobiol Dis 57:47-55. doi:10.1016/j.nbd.2012.06.011 
10. Cotman CW, Berchtold NC (2002) Exercise: a behavioral intervention to enhance brain health and plasticity. Trends Neurosci 25(6):295-301

11. Norton S, Matthews FE, Barnes DE, Yaffe K, Brayne C (2014) Potential for primary prevention of Alzheimer's disease: an analysis of population-based data. Lancet Neurol 13(8):788-794. doi:10.1016/S1474-4422(14)70136-X

12. Llorens-Martin M, Torres-Aleman I, Trejo JL (2008) Growth factors as mediators of exercise actions on the brain. Neuromol Med 10(2):99-107. doi:10.1007/s12017-008-8026-1

13. Cotman CW, Berchtold NC, Christie LA (2007) Exercise builds brain health: key roles of growth factor cascades and inflammation. Trends Neurosci 30(9):464-472. doi:10.1016/j.tins.2007.06.011

14. Liu HL, Zhao G, Zhang H, Shi LD (2013) Long-term treadmill exercise inhibits the progression of Alzheimer's disease-like neuropathology in the hippocampus of APP/PS1 transgenic mice. Behav Brain Res 256:261-272. doi:10.1016/j.bbr.2013.08.008

15. Vivar C, Potter MC, van Praag H (2013) All about running: synaptic plasticity, growth factors and adult hippocampal neurogenesis. Curr Top Behav Neurosci 15:189-210. doi:10.1007/ 7854_2012_220

16. Meshi D, Drew MR, Saxe M, Ansorge MS, David D, Santarelli L, Malapani C, Moore H, Hen R (2006) Hippocampal neurogenesis is not required for behavioral effects of environmental enrichment. Nat Neurosci 9(6):729-731. doi:10.1038/nn1696

17. Lazarov O, Mattson MP, Peterson DA, Pimplikar SW, van Praag $H$ (2010) When neurogenesis encounters aging and disease. Trends Neurosci 33(12):569-579. doi:10.1016/j.tins.2010.09.003

18. Llorens-Martin M, Fuster-Matanzo A, Teixeira CM, Jurado-Arjona J, Ulloa F, Defelipe J, Rabano A, Hernandez F, Soriano E, Avila J (2013) GSK-3beta overexpression causes reversible alterations on postsynaptic densities and dendritic morphology of hippocampal granule neurons in vivo. Mol Psychiatry 18(4):451-460. doi:10.1038/mp.2013.4

19. Llorens-Martin M, Jurado-Arjona J, Fuster-Matanzo A, Hernandez F, Rabano A, Avila J (2014) Peripherally triggered and GSK3beta-driven brain inflammation differentially skew adult hippocampal neurogenesis, behavioral pattern separation and microglial activation in response to ibuprofen. Transl Psychiatry 4:e463. doi:10.1038/tp.2014.92

20. Gingrich JR, Roder J (1998) Inducible gene expression in the nervous system of transgenic mice. Annu Rev Neurosci 21:377-405. doi:10.1146/annurev.neuro.21.1.377

21. Gossen M, Bujard H (1992) Tight control of gene expression in mammalian cells by tetracycline-responsive promoters. Proc Natl Acad Sci USA 89(12):5547-5551

22. Lucas JJ, Hernandez F, Gomez-Ramos P, Moran MA, Hen R, Avila J (2001) Decreased nuclear beta-catenin, tau hyperphosphorylation and neurodegeneration in GSK-3beta conditional transgenic mice. EMBO J 20(1-2):27-39. doi:10.1093/emboj/20. 1.27

23. Zhu Z, Zheng T, Lee CG, Homer RJ, Elias JA (2002) Tetracycline-controlled transcriptional regulation systems: advances and application in transgenic animal modeling. Semin Cell Dev Biol 13(2):121-128

24. Baron U, Freundlieb S, Gossen M, Bujard H (1995) Co-regulation of two gene activities by tetracycline via a bidirectional promoter. Nucleic Acids Res 23(17):3605-3606

25. Bergami M, Masserdotti G, Temprana SG, Motori E, Eriksson TM, Gobel J, Yang SM, Conzelmann KK, Schinder AF, Gotz M, Berninger B (2015) A critical period for experience-dependent remodeling of adult-born neuron connectivity. Neuron 85(4):710-717. doi:10.1016/j.neuron.2015.01.001

26. Llorens-Martin M, Torres-Aleman I, Trejo JL (2006) Pronounced individual variation in the response to the stimulatory action of exercise on immature hippocampal neurons. Hippocampus 16(5):480-490. doi:10.1002/hipo.20175

27. Sholl DA (1955) The organization of the visual cortex in the cat. J Anat 89(1):33-46

28. Rodriguez A, Ehlenberger DB, Dickstein DL, Hof PR, Wearne SL (2008) Automated three-dimensional detection and shape classification of dendritic spines from fluorescence microscopy images. PLoS One 3(4):e1997. doi:10.1371/journal. pone.0001997

29. Arellano JI, Benavides-Piccione R, Defelipe J, Yuste R (2007) Ultrastructure of dendritic spines: correlation between synaptic and spine morphologies. Front Neurosci 1(1):131-143. doi:10. 3389/neuro.01.1.1.010.2007

30. Fuster-Matanzo A, Llorens-Martin M, Sirerol-Piquer MS, GarciaVerdugo JM, Avila J, Hernandez F (2013) Dual effects of increased glycogen synthase kinase-3beta activity on adult neurogenesis. Hum Mol Genet 22(7):1300-1315. doi:10.1093/hmg/ dds533

31. Liu SJ, Zhang JY, Li HL, Fang ZY, Wang Q, Deng HM, Gong CX, Grundke-Iqbal I, Iqbal K, Wang JZ (2004) Tau becomes a more favorable substrate for GSK-3 when it is prephosphorylated by PKA in rat brain. J Biol Chem 279(48):50078-50088. doi:10. 1074/jbc.M406109200

32. Eom TY, Jope RS (2009) Blocked inhibitory serine-phosphorylation of glycogen synthase kinase-3alpha/beta impairs in vivo neural precursor cell proliferation. Biol Psychiatry 66(5):494-502. doi:10.1016/j.biopsych.2009.04.015

33. Fuster-Matanzo A, de Barreda EG, Dawson HN, Vitek MP, Avila J, Hernández F (2009) Function of tau protein in adult newborn neurons. FEBS Lett 583(18):3063-3068. doi:10.1016/j.febslet. 2009.08.017

34. Gould E, McEwen BS (1993) Neuronal birth and death. Curr Opin Neurobiol 3(5):676-682

35. Kelsch W, Lin CW, Lois C (2008) Sequential development of synapses in dendritic domains during adult neurogenesis. Proc Natl Acad Sci USA 105(43):16803-16808. doi:10.1073/pnas. 0807970105

36. Bischofberger $\mathbf{J}$ (2007) Young and excitable: new neurons in memory networks. Nat Neurosci 10(3):273-275. doi:10.1038/ nn0307-273

37. Clelland CD, Choi M, Romberg C, Clemenson GD Jr, Fragniere A, Tyers P, Jessberger S, Saksida LM, Barker RA, Gage FH, Bussey TJ (2009) A functional role for adult hippocampal neurogenesis in spatial pattern separation. Science 325(5937): 210-213. doi:10.1126/science.1173215

38. Nakashiba T, Cushman JD, Pelkey KA, Renaudineau S, Buhl DL, McHugh TJ, Rodriguez Barrera V, Chittajallu R, Iwamoto KS, McBain CJ, Fanselow MS, Tonegawa S (2012) Young dentate granule cells mediate pattern separation, whereas old granule cells facilitate pattern completion. Cell 149(1):188-201. doi:10. 1016/j.cell.2012.01.046

39. Johnston ST, Shtrahman M, Parylak S, Goncalves JT, Gage FH (2015) Paradox of pattern separation and adult neurogenesis: a dual role for new neurons balancing memory resolution and robustness. Neurobiol Learn Mem. doi:10.1016/j.nlm.2015.10. 013

40. Feng R, Rampon C, Tang YP, Shrom D, Jin J, Kyin M, Sopher B, Miller MW, Ware CB, Martin GM, Kim SH, Langdon RB, Sisodia SS, Tsien JZ (2001) Deficient neurogenesis in forebrainspecific presenilin-1 knockout mice is associated with reduced clearance of hippocampal memory traces. Neuron 32(5):911-926

41. Demars M, Hu YS, Gadadhar A, Lazarov O (2010) Impaired neurogenesis is an early event in the etiology of familial Alzheimer's disease in transgenic mice. $J$ Neurosci Res 88(10):2103-2117. doi:10.1002/jnr.22387 
42. Gomez-Nicola D, Suzzi S, Vargas-Caballero M, Fransen NL, AlMalki H, Cebrian-Silla A, Garcia-Verdugo JM, Riecken K, Fehse B, Perry VH (2014) Temporal dynamics of hippocampal neurogenesis in chronic neurodegeneration. Brain $137(\mathrm{Pt}$ 8):2312-2328. doi:10.1093/brain/awu155

43. Pei JJ, Tanaka T, Tung YC, Braak E, Iqbal K, Grundke-Iqbal I (1997) Distribution, levels, and activity of glycogen synthase kinase-3 in the Alzheimer disease brain. J Neuropathol Exp Neurol 56(1):70-78

44. Takashima A, Noguchi K, Sato K, Hoshino T, Imahori K (1993) Tau protein kinase I is essential for amyloid beta-protein-induced neurotoxicity. Proc Natl Acad Sci USA 90(16):7789-7793

45. Planel E, Yasutake K, Fujita SC, Ishiguro K (2001) Inhibition of protein phosphatase $2 \mathrm{~A}$ overrides tau protein kinase I/glycogen synthase kinase 3 beta and cyclin-dependent kinase 5 inhibition and results in tau hyperphosphorylation in the hippocampus of starved mouse. J Biol Chem 276(36):34298-34306. doi:10.1074/ jbc.M102780200

46. Stancu IC, Ris L, Vasconcelos B, Marinangeli C, Goeminne L, Laporte V, Haylani LE, Couturier J, Schakman O, Gailly P, Pierrot N, Kienlen-Campard P, Octave JN, Dewachter I (2014) Tauopathy contributes to synaptic and cognitive deficits in a murine model for Alzheimer's disease. FASEB J 28(6): 2620-2631. doi:10.1096/fj.13-246702

47. Peineau S, Taghibiglou C, Bradley C, Wong TP, Liu L, Lu J, Lo E, Wu D, Saule E, Bouschet T, Matthews P, Isaac JT, Bortolotto ZA, Wang YT, Collingridge GL (2007) LTP inhibits LTD in the hippocampus via regulation of GSK3beta. Neuron 53(5): 703-717. doi:10.1016/j.neuron.2007.01.029

48. Lesort M, Jope RS, Johnson GV (1999) Insulin transiently increases tau phosphorylation: involvement of glycogen synthase kinase-3beta and Fyn tyrosine kinase. J Neurochem 72(2): 576-584

49. Yuskaitis CJ, Jope RS (2009) Glycogen synthase kinase-3 regulates microglial migration, inflammation, and inflammationinduced neurotoxicity. Cell Signal 21(2):264-273. doi:10.1016/j. cellsig.2008.10.014

50. Amaral DG (1978) A Golgi study of cell types in the hilar region of the hippocampus in the rat. $\mathrm{J}$ Comp Neurol 182(4 Pt 2):851-914

51. Witter MP, Amaral DG (1991) Entorhinal cortex of the monkey: V. Projections to the dentate gyrus, hippocampus, and subicular complex. J Comp Neurol 307(3):437-459. doi:10.1002/cne. 903070308

52. Solas M, Aisa B, Mugueta MC, Del Rio J, Tordera RM, Ramirez MJ (2010) Interactions between age, stress and insulin on cognition: implications for Alzheimer's disease. Neuropsychopharmacology 35(8):1664-1673. doi:10.1038/npp.2010.13

53. von Bohlen und Halbach O (2010) Involvement of BDNF in agedependent alterations in the hippocampus. Front Aging Neurosci 2. doi:10.3389/fnagi.2010.00036

54. Carro E, Trejo JL, Gomez-Isla T, LeRoith D, Torres-Aleman I (2002) Serum insulin-like growth factor I regulates brain amyloid-beta levels. Nat Med 8(12):1390-1397. doi:10.1038/nm793

55. Bhaskar K, Konerth M, Kokiko-Cochran ON, Cardona A, Ransohoff RM, Lamb BT (2010) Regulation of tau pathology by the microglial fractalkine receptor. Neuron 68(1):19-31. doi:10. 1016/j.neuron.2010.08.023
56. King MK, Pardo M, Cheng Y, Downey K, Jope RS, Beurel E (2014) Glycogen synthase kinase-3 inhibitors: rescuers of cognitive impairments. Pharmacol Ther 141(1):1-12. doi:10.1016/j. pharmthera.2013.07.010

57. Chen MJ, Russo-Neustadt AA (2005) Exercise activates the phosphatidylinositol 3-kinase pathway. Brain Res Mol Brain Res 135(1-2):181-193. doi:10.1016/j.molbrainres.2004.12.001

58. Trejo JL, Carro E, Torres-Aleman I (2001) Circulating insulinlike growth factor I mediates exercise-induced increases in the number of new neurons in the adult hippocampus. J Neurosci 21(5):1628-1634

59. Inoue K, Okamoto M, Shibato J, Lee MC, Matsui T, Rakwal R, Soya H (2015) Long-term mild, rather than intense, exercise enhances adult hippocampal neurogenesis and greatly changes the transcriptomic profile of the hippocampus. PLoS One 10(6):e0128720. doi:10.1371/journal.pone.0128720

60. Fabel K, Fabel K, Tam B, Kaufer D, Baiker A, Simmons N, Kuo CJ, Palmer TD (2003) VEGF is necessary for exercise-induced adult hippocampal neurogenesis. Eur J Neurosci 18(10): 2803-2812

61. Neeper SA, Gomez-Pinilla F, Choi J, Cotman CW (1996) Physical activity increases mRNA for brain-derived neurotrophic factor and nerve growth factor in rat brain. Brain Res 726(1-2):49-56

62. Soya $H$, Nakamura $T$, Deocaris CC, Kimpara A, Iimura $M$, Fujikawa T, Chang H, McEwen BS, Nishijima T (2007) BDNF induction with mild exercise in the rat hippocampus. Biochem Biophys Res Commun 358(4):961-967. doi:10.1016/j.bbrc.2007. 04.173

63. Erickson KI, Voss MW, Prakash RS, Basak C, Szabo A, Chaddock L, Kim JS, Heo S, Alves H, White SM, Wojcicki TR, Mailey E, Vieira VJ, Martin SA, Pence BD, Woods JA, McAuley E, Kramer AF (2011) Exercise training increases size of hippocampus and improves memory. Proc Natl Acad Sci USA 108(7):3017-3022. doi:10.1073/pnas.1015950108

64. Cotman CW, Berchtold NC (2007) Physical activity and the maintenance of cognition: learning from animal models. Alzheimers Dement 3(2 Suppl):S30-S37. doi:10.1016/j.jalz.2007.01. 013

65. Radak Z, Hart N, Sarga L, Koltai E, Atalay M, Ohno H, Boldogh I (2010) Exercise plays a preventive role against Alzheimer's disease. J Alzheimers Dis 20(3):777-783. doi:10.3233/JAD2010-091531

66. Foster PP, Rosenblatt KP, Kuljis RO (2011) Exercise-induced cognitive plasticity, implications for mild cognitive impairment and Alzheimer's disease. Front Neurol 2:28. doi:10.3389/fneur. 2011.00028

67. Mirochnic S, Wolf S, Staufenbiel M, Kempermann G (2009) Age effects on the regulation of adult hippocampal neurogenesis by physical activity and environmental enrichment in the APP23 mouse model of Alzheimer disease. Hippocampus 19(10):1008-1018. doi:10.1002/hipo.20560

68. Rao SK, Ross JM, Harrison FE, Bernardo A, Reiserer RS, Reiserer RS, Mobley JA, McDonald MP (2015) Differential proteomic and behavioral effects of long-term voluntary exercise in wild-type and APP-overexpressing transgenics. Neurobiol Dis 78:45-55. doi:10.1016/j.nbd.2015.03.018 